\title{
Coordination of Supply Chain with One Supplier and Two Competing Risk-Averse Retailers under an Option Contract
}

\author{
Rui Wang, ${ }^{1,2}$ Shiji Song, and Cheng Wu ${ }^{1}$ \\ ${ }^{1}$ Department of Automation, Tsinghua University, Beijing 100084, China \\ ${ }^{2}$ Department of Basic Science, Military Transportation University, Tianjin 300161, China \\ Correspondence should be addressed to Shiji Song; shijis@mail.tsinghua.edu.cn
}

Received 23 October 2015; Accepted 31 December 2015

Academic Editor: Paulina Golinska

Copyright (c) 2016 Rui Wang et al. This is an open access article distributed under the Creative Commons Attribution License, which permits unrestricted use, distribution, and reproduction in any medium, provided the original work is properly cited.

\begin{abstract}
This paper studies an option contract for coordinating a supply chain comprising one risk-neutral supplier and two risk-averse retailers engaged in promotion competition in the selling season. For a given option contract, in decentralized case, each riskaverse retailer decides the optimal order quantity and the promotion policy by maximizing the conditional value-at-risk of profit. Based on the retailers' decision, the supplier derives the optimal production policy by maximizing expected profit. In centralized case, the optimal decision of the supply chain system is obtained. Based on the decentralized and centralized decision, we find the coordination conditions of the supply chain system, which can optimize the supply chain system profit and make the profits of the supply chain members achieve Pareto optimum. As for the subchain, we also find the coordination conditions, which generalize the results of the supply chain with one supplier and one retailer. Our analysis and numerical experiments show that there exists a unique Nash equilibrium between two retailers, and the optimal order quantity of each retailer increases (decreases) with its own (competitor's) promotion level.
\end{abstract}

\section{Introduction}

The current business environment is full of uncertainties, including market demand, risk preference, lead times, price fluctuation, and transport. These uncertainties entail new risks in matching supply and demand [1], and these risks inevitably lead to supply chain inefficiency. Such problems have been encountered by companies such as Mattel, Inc., a toy maker [2].

As supply chains become more and more complex, their coordination is an increasingly significant challenge for supply chain agents in industry. With channel coordination, supply chain efficiency has been tremendously improved, and issues involving double marginalization have been well resolved. Coordination among supply chain agents by setting incentive alignment contracts is a hot topic in supply chain management. Various contracts have been shown to achieve coordination in supply chains, such as buyback contracts [3], quantity-flexibility contracts $[4,5]$, sales-rebate contracts [6], quantity-discount contracts [7-9], and revenue-sharing contracts [10]. The option contract is a useful tool to hedge the risk of operations management and can coordinate the supply chain effectively [1, 2, 11-15].

In fact, option contracts have been widely used in many industries and are becoming popular in supply chain management. For example, option contracts are used for $35 \%$ of Hewlett-Packard's procurement value. In particular, its purchases of memory chips involve option contracts with its suppliers [11]. Boeing offers option contracts to airlines for purchase of aircraft [16].

Ritchken and Tapiero [17] introduced the option contract to hedge against price and quantity fluctuation risks in inventory control. Tsay [18] showed that the option contract can be used to coordinate the supply chain and increase buyers' replenishment flexibility. Early studies of this issue were based on the assumption that supply chain agents were risk-neutral $[2,11,13,14,19]$, and few papers considered agents' risk preference (such as loss aversion). In fact, the decision-making behavior of managers has been found to deviate from maximizing (expected) profit in a way consistent with loss aversion [20], as shown by many experimental studies and observations of managerial 
decision-making under uncertainty [21-25]. To the authors' knowledge, Gan et al. [26] were the first to study supply chain coordination issues with loss-averse agents. Xu [27] obtained the loss-averse retailer's optimal ordering policy and the supplier's optimal decision under an option contract and demonstrated that both sides can benefit. Zhao et al. [14] demonstrated that option contracts can coordinate the supply chain and achieve Pareto improvement using a cooperative game approach. Zhao et al. [15] explored supply chain coordination with bidirectional option contracts and derived a closed-form expression for the retailer's optimal order strategies with a general demand distribution. Chen et al. [1] investigated supply chain coordination issues with a risk-neutral supplier and a risk-averse retailer and proved that option contracts can make the supply chain achieve the Pareto optimum. Obviously, the above research is only concerned with the coordination of supply chain upstream and downstream.

In the real environment, the supply chain coordination should be involved in both the upstream and downstream, but also in the same layer. Ingene and Parry [28] explored the wholesale pricing behavior within a two-level vertical channel consisting of a manufacturer selling through multiple independent retailers and analyzed the optimality of channel coordination for all channel members. Padmanabhan and Png [29] examined the manufacturer's return policy for two competing retailers with and without demand uncertainty. Yao et al. [30] further considered the manufacturer's return policy in a newsboy model in which the random demand faced by two competing retailers was sensitive to retail price. Xiao et al. [31] studied a supply chain coordination model with a price-subsidy rate contract, in which there were one manufacturer and two competing retailers. Xiao and Qi [32] investigated the coordination of a supply chain with one manufacturer and two competing retailers, using two mechanisms, after the production cost of the manufacturer was disrupted. However, above researches did not involve option contracts and the supply chain agents are risk-neutral.

Generally, high risk implies high return, but also high loss. A risk-averse individual would prefer to receive a relatively lower return to avoid a potential huge loss. When decision-makers focus on risk control, a number of riskrelated performance criteria may be used to measure the risk caused by uncertainty in supply chain management. Specifically, conditional value-at-risk, defined as the weighted average of value-at-risk and losses strictly exceeding VaR, has attracted much attention in recent years and has been widely used in finance, insurance, and supply chain management. $\mathrm{CVaR}$ is a consistent risk measure with better properties and computing performance than other measures [33, 34]. Yang et al. [35] researched supply chain coordination with a riskaverse retailer and a risk-neutral supplier and showed that the supply chain can achieve channel coordination in a CVaR framework with revenue-sharing, buyback, two-part tariffs, and flexible-quantity contracts. Chen et al. [1] discussed supply chain coordination with a loss-averse retailer under an option contract, although they used the prospective theory to describe the retailer's risk preference. Chen et al. [36] studied stable and coordinating contracts for a supply chain with multiple risk-averse suppliers under a CVaR objective. Wu et al. [37] considered a risk-averse newsvendor problem with quantity and price competition under the CVaR criterion. Hsieh and $\mathrm{Lu}$ [38] extended the work of Padmanabhan and Png [29] and Yao et al. [30] researched manufacturer's return policy in a two-stage supply chain with two risk-averse retailers and random demand via $\mathrm{CVaR}$.

Different from the work of Zhao et al. [14], Chen et al. [36], Wu et al. [37], and Hsieh and Lu [38], we investigate the coordination of supply chain with a risk-neutral supplier and two risk-averse retailers engaged in promotional competition based on an option contract and a CVaR criterion. This paper will focus on the following problems: (1) What are the optimal order quantity and the promotion policies of the two riskaverse retailers engaged in promotional competition with a CVaR criterion and what is the risk-neutral supplier's optimal production decision in the presence of an option contract and a CVaR criterion? What are the characteristics of these decisions? (2) Does there exist a unique equilibrium point between two risk-averse retailers engaged in promotional competition? (3) How can a supply chain with two risk-averse retailers engaged in promotional competition be coordinated based on an option contract and a CVaR criterion? (4) What is the impact of the promotional competition on the retailer's optimal ordering policy, the supplier's optimal production decision, and supply chain coordination?

To address these problems, the following scenario will be studied. There are two risk-averse retailers engaged in promotional competition, who are selling the same products. The demand for each retailer is stochastic and depends partially on the retailer's promotion level. In the decentralized case, the objective of each risk-averse retailer is to maximize his conditional value-at-risk of profit, and the supplier's goal is to maximize his expected profit. The existence of equilibrium point between two risk-averse retailers engaged in promotional competition will then be explored. In the centralized case, the optimal decisions for the supply chain system-wide will be discussed. The purpose of this study is to investigate supply chain coordination issues and to explore the impact of promotional competition on the retailers' optimal order quantity, the supplier's optimal production decision, and supply chain coordination. To the best of the authors' knowledge, this problem has not been considered in a situation with an option contract and a CVaR criterion. This paper differs from existing research on supply chain coordination in three aspects. First, there exists a unique Nash equilibrium between two retailers, and the impacts of the promotion level on the retailer's equilibrium option order quantity are analyzed. Secondly, the impact of a shortage penalty cost on the supplier's optimal production decision is considered. Finally, the coordination conditions for such a supply chain under the option contract and the CVaR criterion are obtained.

The remainder of this paper is organized as follows. Section 2 presents the model formulation and the assumptions made. Section 3 describes the decentralized case, involving the optimal option order quantity and the promotion policy of two retailers under an option contract and 
a CVaR criterion and the supplier's optimal production decision under an option contract. The equilibrium competition between two risk-averse retailers is also analyzed. Section 4 explores supply chain system and its subchain coordination issues, and the corresponding coordination conditions are given. Section 5 illustrates the impact of the promotion level on the optimal order quantity of each retailer through numerical experiments. Section 6 concludes the paper.

\section{Model Formulation and Assumptions}

Let us consider a one-period, two-echelon supply chain coordination problem. The supply chain consists of one riskneutral supplier and two risk-averse retailers engaged in promotion competition. In the traditional Cournot competition, the demand is considered as the determination [10], but, in fact, the demand is uncertain. We assume that two retailers order the product from the supplier with demand uncertainty. The uncertain demand faced by retailer $i$ ( $i=$ $1,2)$ is $D_{i}$, which takes on an additive form, and can be expressed as $D_{i}=d_{i}+X_{i} \cdot d_{i} \geqslant 0$ is a demand relating to the market scale and promotion level. We assume that $d_{i}=d_{i}\left(e_{i}, e_{3-i}\right)$ is a linear function, increasing (decreasing) monotonically with the retailer's (the competitor's) promotion level $e_{i}\left(e_{3-i}\right)$, which can be described by the amount of promotional products. Let $g_{i}\left(e_{i}\right)$ denote the promotional cost of retailer $i$, which is a second-order differentiable function satisfying $g_{i}(0)=0$. Let $G_{i}=g_{i}^{\prime}\left(e_{i}\right)$ be a monotonically increasing function, with its inverse function denoted as $G_{i}^{-1}$, $H_{i}=g_{i}^{\prime \prime}\left(e_{i}\right)>0 . X_{i}$ is a continuous, differentiable, and invertible random variable, which is independent of $d_{i}$. For simplicity, let $X_{i}$ have the same probability density function $f(x)$ and cumulative distribution function $F(x) . F(x)$ is nonnegative, strictly increasing, and invertible and satisfies $F(0)=0$ and $\bar{F}(x)=1-F(x) . D$ is total market demand, $D=D_{1}+D_{2}$, which increases monotonically with the total promotion level.

The product is perishable, with a comparatively long lead time and a short selling season. This paper focuses on activities from the beginning of the production season to the end of the selling season. At the beginning of the production season, retailer $i$ and the supplier sign an option contract with two parameters, denoted as $\left(O_{i}, E_{i}\right)$, where $O_{i}$ is the option price and $E_{i}$ is the exercise price. At the same time, each retailer purchases an option quantity, denoted as $q_{i}$, at unit price $O_{i}$. Then the supplier makes his production decision based on the retailers' option order quantities and begins to produce. In the selling season, depending on actual demand, retailers begin to exercise their option quantities. The unit sale price of retailer $i$ is $P_{i}$, and the unit production cost of the supplier is $C$. If the supplier fails to complete the option order quantity exercised by the retailers, then the retailers have the right to punish the supplier by shortage penalty cost, denoted as $Z_{i}$, which is the cost to the supplier to obtain an additional unit of product by expediting production or buying from an alternative source.

Without loss of generality, it is assumed that the salvage of the supplier and retailers is zero and that there are no credit losses for retailers in an out-of-stock situation. To avoid trivial problem and to ensure profit for all parties, it is assumed that $C<O_{i}+E_{i}<P_{i}$. The notation $x^{+}=\max \{0, x\}$ will be used.

\section{Retailers' Optimal Option Order Policy}

At the beginning of the production season, retailer $i$ purchases an option order quantity $q_{i}$ with an option contract. When retailer $i$ is risk-neutral, the profit of retailer $i$, denoted as $\pi_{i}^{r}\left(q_{i}, e_{i}, D_{i}\right)$, is

$$
\begin{aligned}
\pi_{i}^{r}\left(q_{i}, e_{i}, D_{i}\right)= & P_{i} \min \left(q_{i}, D_{i}\right)-O_{i} q_{i}-E_{i} \min \left(q_{i}, D_{i}\right) \\
& -g_{i}\left(e_{i}\right)
\end{aligned}
$$

In (1), the first term is the sales revenue, the second term is the option cost, the third term is the exercise cost, and the last term is the promotional cost.

Then the corresponding expected profit, denoted as $E\left[\pi_{i}^{r}\right]$, is

$$
\begin{aligned}
E\left[\pi_{i}^{r}\right]= & \left(P_{i}-O_{i}-E_{i}\right) q_{i}-g_{i}\left(e_{i}\right) \\
& -\left(P_{i}-E_{i}\right) \int_{0}^{q_{i}-d_{i}} F(x) d x .
\end{aligned}
$$

Because retailer $i$ is risk-averse, the degree of risk aversion should be taken into account in determining the option order quantity. In this paper, retailer $i$ takes the CVaR as his performance measure because the $\mathrm{CVaR}$ risk measure is a relatively conservative decision-making criterion [35].

According to the definition given by Rockafellar and Uryasev [33], the definition of the CVaR on retailer i's option order quantity and promotion level is given by the following.

Definition 1. $\eta_{i}-\mathrm{CVaR}$ on retailer $i$ 's option order quantity $q_{i}$ and promotion level $e_{i}$, denoted as $C_{\eta_{i}}\left[\pi_{i}^{r}\right]$, is

$$
\begin{aligned}
C_{\eta_{i}} & {\left[\pi_{i}^{r}\right]=E\left\{\pi_{i}^{r}\left(q_{i}, e_{i}, D_{i}\right) \mid \pi_{i}^{r}\left(q_{i}, e_{i}, D_{i}\right)\right.} \\
& \left.\leqslant \beta_{\eta_{i}}\left[\pi_{i}^{r}\left(q_{i}, e_{i}, D_{i}\right)\right]\right\}
\end{aligned}
$$

where $\beta_{\eta_{i}}\left[\pi_{i}^{r}\left(q_{i}, e_{i}, D_{i}\right)\right]=\inf \left\{\beta \mid P\left[\pi_{i}^{r}\left(q_{i}, e_{i}, D_{i}\right) \leqslant \beta\right] \geqslant \eta_{i}\right\}$ is a quantile and $\eta_{i} \in(0,1]$ reflects the degree of risk aversion for retailer $i$ (the smaller $\eta_{i}$ is, the more risk-averse retailer $i$ is).

To facilitate the calculation, an equivalent definition is given by $[33,34]$

$$
C_{\eta_{i}}\left[\pi_{i}^{r}\right]=\max _{\alpha \in \mathbf{R}}\left\{\alpha-\frac{1}{\eta_{i}} E\left[\alpha-\pi_{i}^{r}\left(q_{i}, e_{i}, D_{i}\right)\right]^{+}\right\},
$$

where $\alpha$ is a real number. Let

$$
U_{i}=\alpha-\frac{1}{\eta_{i}} E\left[\alpha-\pi_{i}^{r}\left(q_{i}, e_{i}, D_{i}\right)\right]^{+} .
$$

Combining expressions (2) and (5), with some algebra, yields 


$$
U_{i}= \begin{cases}\alpha, & \alpha \leqslant W_{i}, \\ \alpha-\frac{1}{\eta_{i}} \int_{0}^{\left(\alpha-W_{i}\right) / A_{i}}\left(\alpha-W_{i}-A_{i} x\right) f(x) d x, & W_{i}<\alpha \leqslant V_{i}, \\ \alpha-\frac{1}{\eta_{i}} \int_{0}^{C_{i}}\left(\alpha-W_{i}-A_{i} x\right) f(x) d x-\frac{1}{\eta_{i}} \int_{C_{i}}^{\infty}\left(\alpha-V_{i}\right) f(x) d x, & \alpha>V_{i},\end{cases}
$$

where $A_{i}=P_{i}-E_{i}, B_{i}=P_{i}-E_{i}-O_{i}, C_{i}=q_{i}-d_{i}, V_{i}=$ $\left(P_{i}-E_{i}-O_{i}\right) q_{i}-g_{i}\left(e_{i}\right)$, and $W_{i}=\left(P_{i}-E_{i}\right) d_{i}-O_{i} q_{i}-g_{i}\left(e_{i}\right)$.

Property 1. $C_{\eta_{i}}\left[\pi_{i}^{r}\right]$ is a strictly differentiable concave function on $\left(q_{i}, e_{i}\right)$.

The objective of retailer $i$ is to maximize his CVaR measure $C_{\eta_{i}}\left[\pi_{i}^{r}\right]$. The optimal solution of (3), denoted as $\left(q_{i}^{*}, e_{i}^{*}\right)$, can be obtained using (3), (6), and Property 1.

Theorem 2. Given the degree of risk aversion $\eta_{i}$ for retailer $i$ and the competitor's promotion level $e_{3-i}$, retailer i's optimal option ordering policy is given by

$$
\begin{aligned}
q_{i}^{*} & =d_{i}\left(e_{i}^{*}, e_{3-i}\right)+F^{-1}\left(G_{\eta_{i}}\right), \\
e_{i}^{*}= & G_{i}^{-1}\left(B_{i} m_{i i}\right), \\
C_{\eta_{i}}^{*}\left[\pi_{i}^{r}\left(q_{i}^{*}, e_{i}^{*}\right)\right]= & \frac{A_{i}}{\eta_{i}} \int_{0}^{G_{\eta_{i}}} F^{-1}(t) d t+B_{i} d_{i}\left(e_{i}^{*}, e_{3-i}\right) \\
& -g_{i}\left(e_{i}^{*}\right),
\end{aligned}
$$

where $G_{\eta_{i}}=\left(B_{i} / A_{i}\right) \eta_{i}, m_{i i}=d_{i e_{i}}^{\prime}\left(e_{i}, e_{3-i}\right)$, and $t=F(x)$.

Theorem 2 shows that retailer i's optimal option order quantity contains two parts, one is related to the promotional competition, and the other is determined by stochastic demand. This result is consistent with the form of demand faced by retailers. When retailer $i$ achieves the optimal level of promotional activity $e_{i}^{*}$, retailer $i$ 's option order quantity $q_{i}^{*}$ satisfies the following property.

Property 2. Given the optimal promotion level $e_{i}^{*}$ for retailer $i$, then retailer $i$ 's optimal option order quantity $q_{i}^{*}$ satisfies the following properties: $\partial q_{i}^{*} / \partial O_{i}<0, \partial q_{i}^{*} / \partial E_{i}<0, \partial q_{i}^{*} / \partial \eta_{i}>0$, and $\partial q_{i}^{*} / \partial e_{3-i}<0$.

In Property 2, the first two items show that when the option price and the exercise price rise, retailer $i$ will reduce his cost by reducing the option order quantity to ensure his profit. The third item illustrates that the higher $\eta_{i}$ is, the lower retailer $i$ 's degree of risk aversion will be, making $q_{i}^{*}$ higher. This result is consistent with the intuition that risk-averse retailers would rather have a steady income than take a risk to obtain more benefit. When $\eta_{i}=1$, retailer $i$ is risk-neutral, and retailer $i$ 's optimal order policy $\left(q_{i}^{0 *}, e_{i}^{0 *}\right)$ is

$$
\begin{aligned}
& q_{i}^{0 *}=d_{i}\left(e_{i}^{0 *}, e_{3-i}\right)+F^{-1}\left(G_{0}\right), \\
& e_{i}^{0 *}=G_{i}^{-1}\left(B_{i} m_{i i}\right),
\end{aligned}
$$

where $G_{0}=B_{i} / A_{i}$. Obviously, $q_{i}^{*}<q_{i}^{0 *}$ and $e_{i}^{*}<e_{i}^{0 *}$. Wang and Webster [12] derived a similar conclusion; however, their result is based on a whole-price contract for a supply chain with a loss-averse retailer. The last item in Property 2 indicates that the higher the competitor's promotion level is, the lower the retailer $i$ 's optimal option order quantity will be, and corresponding profit will be reduced. When retailer 1 is in his best promotional environment, the upper bound on $q_{1}^{*}$ is obtained when $e_{2}=0$ in (7), and the lower bound on $q_{1}^{*}$ is obtained when $e_{2} \rightarrow \infty$ in (7). Therefore, the curve $q_{1}=q_{1}^{*}\left(e_{1}^{*}, e_{2}\right)$ is the reaction curve on $\left(e_{1}, e_{2}\right)$ for retailer 1 , as illustrated in Figure 1.

If $q_{2}^{*}\left(e_{1}, e_{2}^{*}\right)$ is retailer 2's optimal option order quantity, similar conclusions will be obtained. Figure 1 also illustrates the reaction curve of retailer 2 , that is, the curve $q_{2}=$ $q_{2}^{*}\left(e_{1}, e_{2}^{*}\right)$. As illustrated in Figure 1 , there is an equilibrium point between the two retailers. At the equilibrium point, if each retailer knows the best level of promotional activity of the other, then the two retailers' competition satisfies the following equilibrium equations:

$$
\begin{array}{ll}
C_{\eta_{1}}\left[\pi_{1}^{r}\left(q_{1}^{*}, \mathbf{e}^{*}\right)\right] \geqslant C_{\eta_{1}}\left[\pi_{1}^{r}\left(q_{1}, e_{1}, e_{2}^{*}\right)\right], & \forall q_{1}, e_{1} \geqslant 0, \\
C_{\eta_{2}}\left[\pi_{2}^{r}\left(q_{2}^{*}, \mathbf{e}^{*}\right)\right] \geqslant C_{\eta_{2}}\left[\pi_{2}^{r}\left(q_{2}, e_{2}, e_{1}^{*}\right)\right], \quad \forall q_{2}, e_{2} \geqslant 0,
\end{array}
$$

where $\mathbf{e}^{*}=\left(e_{1}^{*}, e_{2}^{*}\right)$.

The next theorem shows the existence and uniqueness of Nash equilibrium between the two retailers.

Theorem 3. Given that each of the two risk-averse retailers knows the best promotion level for the other, then there exists a unique Nash equilibrium between the order quantities of two retailers engaging in promotion competition, and the equilibrium satisfies the following conditions:

$$
\begin{aligned}
& q_{i}^{*}=d_{i}^{*}+F^{-1}\left(G_{\eta_{i}}\right), \\
& e_{i}^{*}=G_{i}^{-1}\left(B_{i} m_{i i}\right),
\end{aligned}
$$

where $d_{i}^{*}=d_{i}\left(e_{i}^{*}, e_{3-i}^{*}\right)$.

Theorem 3 indicates that at the equilibrium point, $q_{1}^{*}=$ $q_{2}^{*}$, it is possible to obtain the relationship of the two retailers on sale price, option price, exercise price, and degree of risk aversion for retailer $i$; that is, $B_{1}=B_{2}$ and $\eta_{1} / \eta_{2}=A_{1} / A_{2}$. The first item indicates that the two retailers have the same profit per unit of product (promotional cost is not considered), and the second item shows that the two retailers' degree of risk aversion is proportional to the difference between the sale price and the exercise price (excluding the sale price, option 


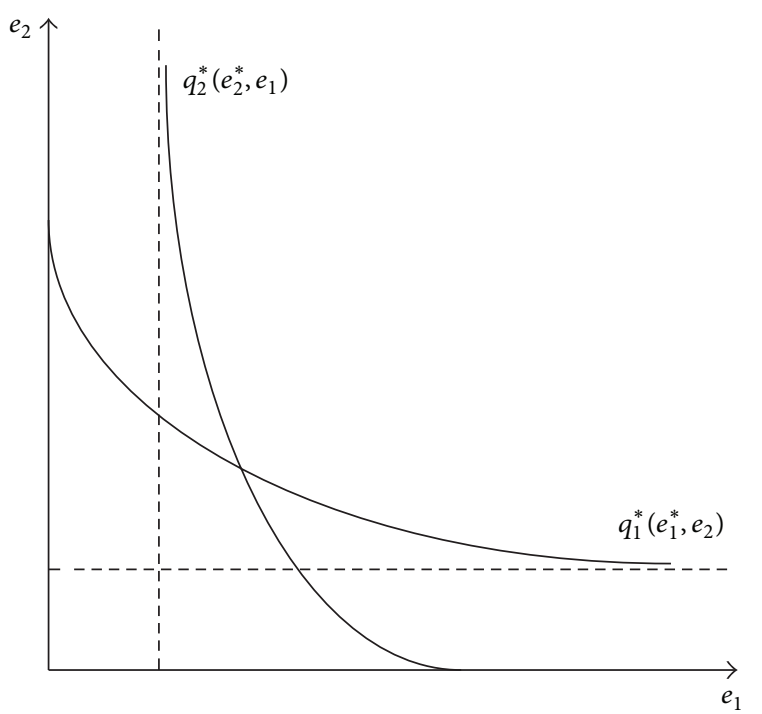

FIGURE 1: Impact of the promotion level on equilibrium order quantity.

price, and exercise price, and degree of risk aversion of the two retailers is the same).

\section{Supplier's Optimal Production Decision}

Before the production season, the supplier will determine the production quantity in accordance with the retailers' option order quantity. Considering that the two retailers will not exercise all their options at the beginning of the selling season, the supplier will reduce production by running the risk of being punished. The supplier's profit, denoted by $\pi^{m}$, is

$$
\begin{aligned}
\pi^{m} & =\sum_{i=1}^{2} \pi_{i}^{m}=\sum_{i=1}^{2}\left\{O_{i} q_{i}^{*}+E_{i} \min \left(q_{i}^{*}, D_{i}\right)-C q_{i}^{m}\right. \\
& \left.-Z_{i}\left[\min \left(q_{i}^{*}, D_{i}\right)-q_{i}^{m}\right]^{+}\right\},
\end{aligned}
$$

where $\pi_{i}^{m}$ is the profit from the supplier's selling of the production to retailer $i$ and $q_{i}^{m}$ is the supplier's option production for retailer $i$. On the right-hand side of the sum in (12), the first term is the option cost that retailer $i$ pays to the supplier, the second term is the supplier's revenue when retailers exercise their options, the third term is the production cost, and the last term is the shortage penalty cost. The corresponding expected profit is

$$
\begin{aligned}
& E\left[\pi^{m}\right]=\sum_{i=1}^{2} E\left[\pi_{i}^{m}\right]=\sum_{i=1}^{2}\left[\left(O_{i}+E_{i}\right) q_{i}^{*}-C q_{i}^{m}\right. \\
& -E_{i} \int_{0}^{q_{i}^{*}-d_{i}\left(e_{i}^{*}, e_{3-i}\right)} F(x) d x \\
& \left.\quad-Z_{i} \int_{q_{i}^{m}-d_{i}\left(e_{i}^{*}, e_{3-i}\right)}^{q_{i}^{*}-d_{i}\left(e_{i}^{*}, e_{3-i}\right)} \bar{F}(x) d x\right] .
\end{aligned}
$$

Property 3. $E\left[\pi^{m}\right]$ is a second-order differentiable function in $q_{i}^{m}$ and satisfies the following properties:

$$
\begin{aligned}
& \frac{\partial E\left[\pi_{i}^{m}\right]}{\partial O_{i}}>0, \\
& \frac{\partial E\left[\pi_{i}^{m}\right]}{\partial E_{i}}>0, \\
& \frac{\partial E\left[\pi_{i}^{m}\right]}{\partial C}<0, \\
& \frac{\partial E\left[\pi_{i}^{m}\right]}{\partial Z_{i}}<0 .
\end{aligned}
$$

Property 3 shows that the higher the option price and the exercise price are, the higher $E\left[\pi_{i}^{m}\right]$ will be, and the higher the production cost and the penalty cost are, the lower $E\left[\pi_{i}^{m}\right]$ will be. These results are consistent with our intuition and the actual situation.

In the proof of Property 3, letting the first-order partial derivative of $E\left[\pi_{i}^{m}\right]$ with respect to $q_{i}^{m}$ be equal to zero,

$$
\frac{\partial E\left[\pi_{i}^{m}\right]}{\partial q_{i}^{m}}=-C+Z_{i}-Z_{i} F\left(q_{i}^{m}-d_{i}\left(e_{i}^{*}, e_{3-i}\right)\right)=0 .
$$

According to (15), the supplier's production decision for retailer $i$, denoted as $q_{i}^{m \Delta}$, is given by

$$
q_{i}^{m \Delta}=d_{i}\left(e_{i}^{*}, e_{3-i}\right)+F^{-1}\left(G_{i}^{m}\right),
$$

where $G_{i}^{m}=\left(Z_{i}-C\right) / Z_{i}$

The first-order partial derivative of $q_{i}^{m \Delta}$ with respect to $Z_{i}$ is $\partial q_{i}^{m \Delta} / \partial Z_{i}=C / Z_{i}^{2} f\left(q_{i}^{m \Delta}-d_{i}\left(e_{i}^{*}, e_{3-i}\right)\right)>0$, which implies that, for given $C, e_{i}^{*}$, and $e_{3-i}$, the supplier's production is increasing in $Z_{i}$. In other words, the supplier will choose to produce more options to reduce the loss when the shortage penalty cost increases. But if the shortage penalty cost is greater than a certain critical value, the supplier will produce all the options, or his marginal loss will be greater than the marginal profit. Combining (7) and (15) yields the shortage penalty threshold value:

$$
\widehat{Z}_{i}=\frac{A_{i} C}{A_{i}-B_{i} \eta_{i}} .
$$

The first-order partial derivative of $\widehat{Z}_{i}$ with respect to $\eta_{i}$ is $\partial \widehat{Z}_{i} / \partial \eta_{i}=A_{i} B_{i} C /\left(A_{i}-B_{i} \eta_{i}\right)^{2}>0$, which indicates that the penalty threshold value $\widehat{Z}_{i}$ will be higher when retailer $i$ is not very risk-averse. According to the above analysis, it is clear that the penalty threshold value directly impacts the supplier's production decision. The supplier's optimal production decision for retailer $i$ is given by

$$
q_{i}^{m *}= \begin{cases}q_{i}^{m \Delta}, & Z_{i}<\widehat{Z}_{i}, \\ q_{i}^{*}, & Z_{i} \geqslant \widehat{Z}_{i} .\end{cases}
$$

From (18), it is known that when $Z_{i}$ is less than $\widehat{Z}_{i}$, the supplier will accept the penalty and will produce only $q_{m}^{i \Delta}$ units of 
options for retailer $i$; otherwise, he will produce all option order quantity. At the same time, the total optimal production quantity $q^{m *}$ of the supplier for two retailers is given by

$$
q^{m *}= \begin{cases}q_{1}^{m \Delta}+q_{2}^{m \Delta}, & Z_{1}<\widehat{Z}_{1}, Z_{2}<\widehat{Z}_{2}, \\ q_{1}^{m \Delta}+q_{2}^{*}, & Z_{1}<\widehat{Z}_{1}, Z_{2} \geqslant \widehat{Z}_{2}, \\ q_{1}^{*}+q_{2}^{m \Delta}, & Z_{1} \geqslant \widehat{Z}_{1}, Z_{2}<\widehat{Z}_{2}, \\ q_{1}^{*}+q_{2}^{*}, & Z_{1} \geqslant \widehat{Z}_{1}, Z_{2} \geqslant \widehat{Z}_{2} .\end{cases}
$$

When $\eta_{i}=1$, the penalty threshold value is $\bar{Z}_{i}=A_{i} C / O_{i}$, and the corresponding optimal production decision $q_{i}^{m 0 *}$ of the supplier for retailer $i$ is

$$
q_{i}^{m 0 *}= \begin{cases}q_{i}^{m 0 \Delta}, & Z_{i}<\bar{Z}_{i} \\ q_{i}^{0 *}, & Z_{i} \geqslant \bar{Z}_{i} .\end{cases}
$$

Obviously, $\widehat{Z}_{i}<\bar{Z}_{i}$ and $q_{i}^{m *}<q_{i}^{m 0 *}$.

\section{Supply Chain Coordination}

It is well known that the optimal decision of supply chain system-wide is the benchmark for supply chain coordination. To derive the optimal decision of the channel, the supply chain is taken as one entity, and the profit of the supply chain system is formulated and denoted as $\pi^{s}$ :

$$
\pi^{s}=\sum_{i=1}^{2}\left[P_{i} \min \left(q_{i}^{s}, D_{i}\right)-C q_{i}^{s}-g_{i}\left(e_{i}^{s}\right)\right]
$$

where $q_{i}^{s}$ and $e_{i}^{s}$ are, respectively, the order quantity and the promotion level for retailer $i$ in the supply chain system. On the right-hand side of the sum in (21), the first term is the sales revenue, the second term is the production cost, and the last term is the promotion cost. The corresponding expected profit is

$$
\begin{aligned}
E\left[\pi^{s}\right] & =\sum_{i=1}^{2} E\left[P_{i} \min \left(q_{i}^{s}, D_{i}\right)-C q_{i}^{s}-g_{i}\left(e_{i}^{s}\right)\right] \\
& =\sum_{i=1}^{2}\left[-P_{i} \int_{0}^{q_{i}^{s}-d_{i}^{s}} F(x) d x+\left(P_{i}-C\right) q_{i}^{s}-g_{i}\left(e_{i}^{s}\right)\right] .
\end{aligned}
$$

Obviously, the optimal decision of the supply chain can be obtained by maximizing (22). Let the first-order partial derivative of $E\left[\pi^{s}\right]$ with respect to $q_{i}^{s}$ and $e_{i}^{s}$ be equal to zero:

$$
\begin{aligned}
\frac{\partial E\left[\pi^{s}\right]}{\partial q_{i}^{s}}= & B_{i}^{s}-P_{i} F\left(C_{i}^{s}\right)=0, \\
\frac{\partial E\left[\pi^{s}\right]}{\partial e_{i}^{s}}= & -G_{i}\left(e_{i}^{s}\right)+P_{i} F\left(C_{i}^{s}\right) m_{i i}^{s} \\
& +P_{3-i} F\left(C_{3-i}^{s}\right) m_{3-i, i}^{s}=0,
\end{aligned}
$$

where $C_{i}^{s}=q_{i}^{s}-d_{i}^{s}, i=1,2$. In addition, the leading principle minors of matrix of $E\left[\pi^{s}\right]$ are as follows: $-P_{i} f\left(C_{i}^{s}\right)<$ $0, P_{i} f\left(C_{i}^{s}\right) H_{i}+P_{3-i} f\left(C_{i}^{s}\right) f\left(C_{3-i}^{s}\right)\left(m_{3-i, i}\right)^{2}>0$. The optimal decision for the channel in (22) can be obtained as follows:

$$
\begin{aligned}
& q_{i}^{s *}=d_{i}^{s *}+F^{-1}\left(G_{i}^{s}\right), \\
& e_{i}^{s *}=G_{i}^{-1}\left(m_{i i}^{s} B_{i}^{s}+m_{3-i, i}^{s} B_{3-i}^{s}\right),
\end{aligned}
$$

where $d_{i}^{s *}=d_{i}\left(e_{i}^{s *}, e_{3-i}^{s *}\right), B_{i}^{s}=P_{i}-C, B_{3-i}^{s}=P_{3-i}-C, G_{i}^{s}=$ $B_{i}^{s} / P_{i}, m_{i i}^{s}=d_{i e_{i}^{s}}^{\prime}$, and $m_{3-i, i}^{s}=d_{3-i, e_{i}^{s}}^{\prime}$.

The optimal order quantity and the promotion level of the supply chain system-wide can be used as the benchmark for supply chain coordination to adjust the option parameters. The coordination conditions of supply chain will be given by the following theorem.

Theorem 4. The supply chain of a risk-neutral supplier and two risk-averse retailers engaging in promotion competition with an option contract and a CVaR criterion can be coordinated by the following conditions:

$$
\begin{aligned}
B_{1} & =B_{2}, \\
\frac{\eta_{1}}{\eta_{2}} & =\frac{A_{1}}{A_{2}}, \\
1-\frac{C}{P_{i}} & <\eta_{i} \leqslant 1, \\
m_{i i} & =\frac{B_{i}^{s} m_{i i}^{s}+B_{3-i}^{s} m_{3-i, i}^{s}}{B_{i}}, \\
P_{i} & =E_{i}+\frac{P_{i} O_{i} \eta_{i}}{C-P_{i}\left(1-\eta_{i}\right)}, \\
Z_{i} & \geqslant P_{i}, \\
C & <O_{i}+E_{i}<P_{i} .
\end{aligned}
$$

In Theorem 4, the first two items show that if the supply chain can be coordinated, then the two retailers first achieve competitive equilibrium. The third item implies that retailers are not very risk-averse; that is, retailers will pursue profit by taking some risk. Let $\Delta d_{i}=d_{i}\left(e_{i}+\Delta e_{i}, e_{3-i}\right)-d_{i}\left(e_{i}, e_{3-i}\right), \Delta d_{i}^{s}=$ $d_{i}\left(e_{i}^{s}+\Delta e_{i}, e_{3-i}^{s}\right)-d_{i}\left(e_{i}^{s}, e_{3-i}^{s}\right)$, and $\Delta d_{3-i}^{s}=d_{3-i}\left(e_{3-i}^{s}, e_{i}^{s}+\Delta e_{i}\right)-$ $d_{3-i}\left(e_{3-i}^{s}, e_{i}^{s}\right)$, where $\Delta e_{i}$ is a small change on the promotion level of retailer $i$. The fourth item shows that if the promotion level of retailer $i$ changes $\Delta e_{i}$ units, then retailer $i$ 's demand will change $\Delta d_{i}^{s}$ units, and the other retailer's demand will change $\Delta d_{3-i}^{s}$ units in the centralized case; retailer $i$ 's demand will change $\left(B_{i}^{s} \Delta d_{i}^{s}+B_{3-i}^{s} \Delta d_{3-i}^{s}\right) / B_{i}$ units in the decentralized case. This relationship is brought about by the two retailers' competition and promotional activities. Furthermore, the penalty threshold value must be higher than the sale price, or the supplier will not produce all option order quantity. Finally, by adjusting the parameters of the option contract, the whole supply chain profit can reach the optimum, and the profits of supply chain members can achieve Pareto optimum. 
TABLE 1: Comparison of the coordination conditions of several supply chains.

\begin{tabular}{lccc}
\hline$S C_{1}$ & $S C_{2}$ & $S C_{i}$ & $S C_{3_{i}}$ \\
\hline$Z \geqslant P$ & $Z \geqslant P$ & $Z_{i} \geqslant P_{i}$ & $Z_{i} \geqslant P_{i}$ \\
\hline$P=E+\frac{P O}{C}$ & $P=E+\frac{P O \eta}{C-P(1-\eta)}$ & $P_{i}=E_{i}+\frac{P_{i} O_{i} \eta_{i}}{C-P_{i}\left(1-\eta_{i}\right)}$ & $P_{i}=E_{i}+\frac{P_{i} O_{i}}{C}$ \\
\hline$\eta>1-\frac{C}{P}$ & $\eta_{i}>1-\frac{C}{P_{i}}$ & \\
\hline & $\frac{m_{i i}}{m_{i i}^{s}}=\frac{B_{i}^{s}}{B_{i}}$ & $\frac{m_{i i}}{m_{i i}^{s}}=\frac{B_{i}^{s}}{B_{i}}$ \\
\hline
\end{tabular}

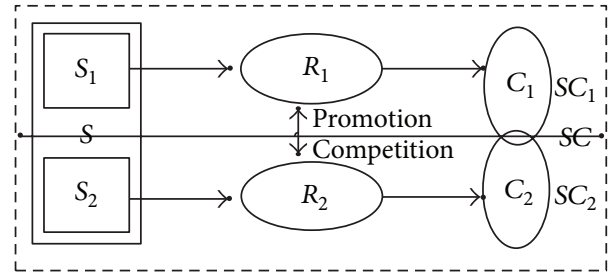

FIGURE 2: The relationship of $S C$ agents.

Then we will discuss the subchain coordination conditions. Figure 2 shows that the supply chain contains two subchains, and the coordination conditions of subchain will be given by the following theorem.

Theorem 5. The subchain $\left(S C_{i}\right)$ can be coordinated by the following conditions:

$$
\begin{aligned}
\eta_{i} & >1-\frac{C}{P_{i}}, \\
Z_{i} & \geqslant P_{i}, \\
P_{i} & =E_{i}+\frac{P_{i} O_{i} \eta_{i}}{C-P_{i}\left(1-\eta_{i}\right)}, \\
\frac{m_{i i}}{m_{i i}^{s}} & =\frac{B_{i}^{s}}{B_{i}}>1 .
\end{aligned}
$$

From Theorem 5, we can see that the first three coordination conditions of $S C_{i}$ are similar to that of the entity supply chain. The last condition implies that $\Delta d_{i}>\Delta d_{i}^{s}$, which means that the level of the promotion activity of retailer $i$ in decentralized decision is higher than in centralized decision.

Furthermore, we can derive the coordination conditions of supply chain with a neutral supplier and a neutral retailer $\left(S C_{1}\right)$, supply chain with a neutral supplier and a risk retailer $\left(S C_{2}\right)$, and subchain of supply chain with a neutral supplier and two neutral retailers engaging in promotion competition $\left(S C_{3_{i}}\right)$. In the coordination conditions of $S C_{i}$, when $\eta_{i}$ and $e_{i}$ are 1 and 0 , respectively, we get the coordination conditions of $S C_{3_{i}}$ and $S C_{2}$, which are consistent with the conclusion of [39], and when $\eta_{i}=1$ and $e_{i}=0$, the coordination conditions of $S C_{1}$ are obtained. Now we compare them in Table 1. From Table 1, we find that the penalty cost is higher than the retail price for four supply chains or subchains coordination conditions. Obviously, this condition is beneficial for the retailers to fully exercise the option, and the supplier has to produce all option order quantity to reduce loss. Table 1 shows that the sale price of $S C_{1}$ is higher than $S C_{2}$, which embodies the characteristic of the retailer's risk aversion. Similar conclusions exist in $S C_{i}$ and $S C_{3_{i}}$.

\section{Numerical Analysis}

In this section, we carry out numerical experiments under the model assumption to illustrate our findings. We let $P_{1}=$ $55, E_{1}=33.5, O_{1}=5.8, P_{2}=54.7, E_{2}=32.6, O_{2}=$ 6.7, $\eta_{1}=0.68, \eta_{2}=0.71, C=27.5$, and $Z_{1}=60$ and $Z_{2}=56$. For simplicity, we assume that the random demand variable of each retailer is uniformly distributed on $[0,300]$, and $d\left(e_{i}, e_{3-i}\right)=100+5 e_{i}-0.43 \cdot 5 e_{3-i}$. The retailers' optimal option order policy and supplier's optimal production decision in decentralized case and the optimal supply chain decision system-wide are shown in Table 2 (note that the data are rounded). In Table 2, retailers' optimal order quantity is the same as the supplier's production decision, and the level of two retailers' promotional activity remains consistent in decentralized case. Furthermore, the optimal profit of supply chain system is the same as that of the retailers and the supplier in decentralized case, which implies that the supply chain consisting of a risk-neutral supplier and two risk-averse retailers in competition and engaged in promotion is coordinated under the option contract and CVaR criterion.

Then we analyze the impact of the level of the promotional activity on the retailers' order quantities by fixing $e_{1}^{*}=85$ and $e_{2}^{*}=85$, respectively, and varying $e_{2}$ and $e_{1}$ from 0 to 200 in steps of 5 corresponding $e_{1}^{*}$ and $e_{2}^{*}$. Figure $3(\mathrm{a})$ shows that retailer 1's order quantity will increase when $e_{1}$ increases; however, retailer 2's order quantity will decrease, similar to Figure 3(b). Figures 3(a) and 3(b) also illustrate the unique equilibrium point between two risk-averse retailers, which is in agreement with the conclusion of Theorem 3.

\section{Conclusion}

This paper investigates an option contract for coordinating a supply chain with one risk-neutral supplier and two riskaverse retailers engaged in promotion competition. Based on the option contract, the optimal option order quantity and the promotion level of two retailers are obtained with CVaR 
TABLE 2: Results on optimal decision in decentralized case and centralized case.

\begin{tabular}{lccccccccccc}
\hline & \multirow{2}{*}{ Retailer } & $e_{1}^{*}$ & $e_{2}^{*}$ & $q_{1}^{r *}$ & $q_{2}^{r *}$ & $q^{r *}$ & $E \pi_{1}^{r *}$ & $E \pi_{2}^{r *}$ & $E \pi^{r *}$ & $\mathrm{CVaR}_{1}^{*}$ & $\mathrm{CVaR}_{2}^{*}$ \\
Decentralized case & & 85 & 85 & 507 & 507 & 114 & 3931 & 3931 & 7862 & 1432 & 1432 \\
& \multirow{3}{*}{ Supplier } & - & - & $q_{1}^{m *}$ & $q_{2}^{m *}$ & $q^{m *}$ & $E \pi_{1}^{m *}$ & $E \pi_{2}^{m *}$ & $E \pi^{m *}$ & - & - \\
& & - & - & 507 & 507 & 114 & 5350 & 5350 & 10700 & - & - \\
\hline \multirow{2}{*}{ Centralized case } & \multirow{2}{*}{ Supply chain } & $e_{1}^{s *}$ & $e_{2}^{s *}$ & $q_{1}^{s *}$ & $q_{2}^{s *}$ & $q^{s *}$ & $E \pi_{1}^{s *}$ & $E \pi_{2}^{s *}$ & $E \pi^{s *}$ & - & - \\
& & 85 & 85 & 507 & 507 & 114 & 9281 & 9281 & 18562 & - \\
\hline
\end{tabular}

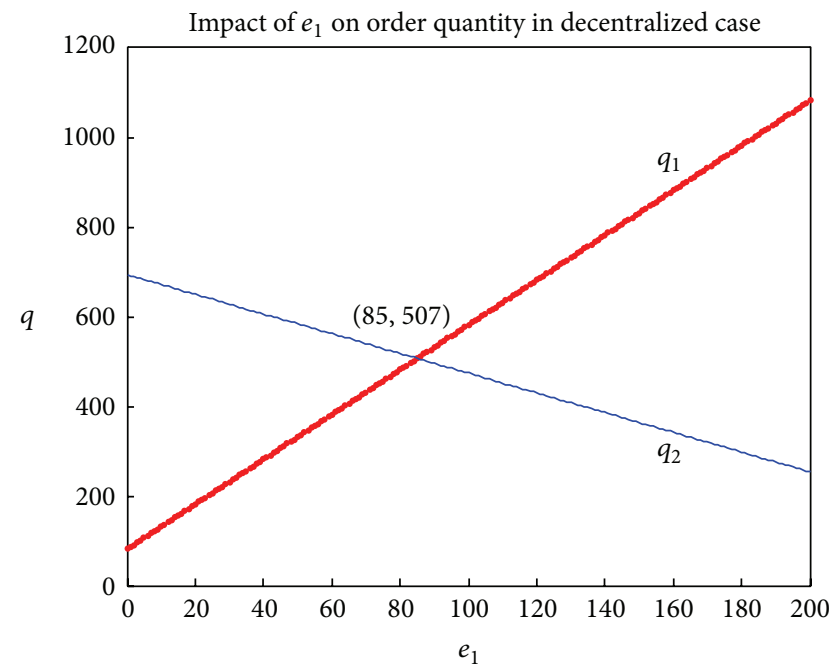

(a)

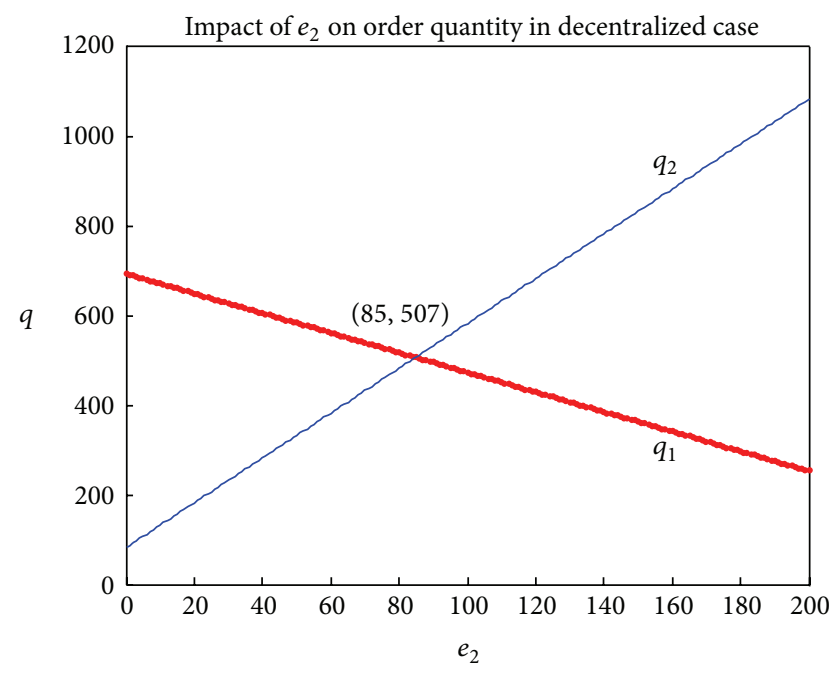

(b)

FIGURE 3: Impact of level of promotional activity on order quantities in decentralized case.

criterion. The impact of the promotion level on the optimal order quantity of each retailer is studied, and a unique Nash equilibrium between two retailers is derived. Based on the retailers' optimal option order policy, the supplier's optimal production decision is further obtained by maximizing expected profit. Furthermore, we discuss the coordination issues of the supply chain system and its subchain and give the corresponding coordination conditions. Both in supply chain and in its subchain, the penalty cost threshold value should be higher than selling price to stimulate the supplier to produce all option order quantity, and the retailers' degree of risk aversion should not be too high. Numerical experiments illustrate the unique Nash equilibrium between two retailers and show that the optimal order quantity of each retailer increases (decreases) with its own (competitor's) promotion level.

Of course, this study includes some limitations which require further exploration in the future. For example, the supply chain that we studied above is assumed to have a risk-neutral supplier, which implies that the supplier has no risk preference. However, it is known that the supplier's risk attitude determines the option price and the exercise price, which will in turn affect the option order quantity and the coordination conditions. Therefore, in future work, the supply chain with a risk-averse supplier and risk-averse retailers can be taken into account.

\section{Appendix}

Proof of Property 1. The first-order and second-order partial derivatives of $U_{i}$ in (6) with respect to $\alpha$ are as follows:

$$
\begin{aligned}
& \frac{\partial U_{i}}{\partial \alpha}= \begin{cases}1, & \alpha_{i} \leqslant W_{i}, \\
1-\frac{1}{\eta_{i}} F\left(\frac{\alpha-W_{i}}{A_{i}}\right), & W_{i}<\alpha \leqslant V_{i}, \\
1-\frac{1}{\eta_{i}}, & \alpha_{i}>V_{i},\end{cases} \\
& \frac{\partial^{2} U_{i}}{\partial \alpha^{2}}= \begin{cases}-\frac{1}{\eta_{i} A_{i}} f\left(\frac{\alpha_{i}-W_{i}}{A_{i}}\right), & W_{i}<\alpha \leqslant V_{i}, \\
0, & \text { others. }\end{cases}
\end{aligned}
$$

Obviously, $\partial^{2} U_{i} / \partial \alpha^{2} \leqslant 0$, which implies that $U_{i}$ is a differentiable concave function of $\alpha$. The stationary point, denoted as $\alpha^{*}\left(q_{i}, e_{i}\right)$, is the maximum point. From (A.1),

$$
\alpha^{*}\left(q_{i}, e_{i}\right)= \begin{cases}V_{i}, & C_{i}<F^{-1}(\alpha), \\ W_{i}+A_{i} F^{-1}\left(\eta_{i}\right), & C_{i} \geqslant F^{-1}(\alpha) .\end{cases}
$$


When $C_{i} \geqslant F^{-1}(\alpha)$, then $W_{i}<\alpha^{*}\left(q_{i}, e_{i}\right)=W_{i}+$ $A_{i} F^{-1}\left(\eta_{i}\right) \leqslant V_{i}$, and

$$
\begin{aligned}
& C_{\eta_{i}}\left[\pi_{i}^{r}\right]=W_{i}+A_{i} F^{-1}\left(\eta_{i}\right)-\frac{1}{\eta_{i}} \\
& \cdot \int_{0}^{\left(\alpha^{*}\left(q_{i} e_{i}\right)-W_{i}\right) / A_{i}}\left(\alpha^{*}\left(q_{i}, e_{i}\right)-W_{i}-A_{i} x\right) \\
& \cdot f(x) d x=W_{i}+A_{i}\left[F^{-1}\left(\eta_{i}\right)-\frac{1}{\eta_{i}}\right. \\
& \left.\cdot \int_{0}^{F^{-1}\left(\eta_{i}\right)} F(x) d x\right] .
\end{aligned}
$$

However, $\partial C_{\eta_{i}}\left[\pi_{i}^{r}\right] / \partial q_{i}=-O_{i}<0$, and therefore the maximum point of $C_{\eta_{i}}\left[\pi_{i}^{r}\right]$ does not exist in this area.

When $C_{i}<F^{-1}\left(\alpha_{i}\right)$, then $\alpha_{i}^{*}\left(q_{i}, e_{i}\right)=V_{i}$, and

$$
\begin{aligned}
C_{\eta_{i}}\left[\pi_{i}^{r}\right]= & V_{i} \\
& -\frac{1}{\eta_{i}} \int_{0}^{\left(V_{i}-W_{i}\right) / A_{i}}\left(V_{i}-W_{i}-A_{i} x\right) f(x) d x \\
= & V_{i}-\frac{1}{\eta_{i}} \int_{0}^{C_{i}} A_{i} F(x) d x .
\end{aligned}
$$

In this case, the Hessian matrix of $C_{\eta_{i}}\left[\pi_{i}^{r}\right]$ on $\left(q_{i}, e_{i}\right)$ is

$$
\left[\begin{array}{cc}
-\frac{A_{i}}{\eta_{i}} f\left(C_{i}\right) & \frac{m_{i i} A_{i}}{\eta_{i}} f\left(C_{i}\right) \\
\frac{m_{i i} A_{i}}{\eta_{i}} f\left(C_{i}\right) & -H_{i}-\frac{\left(m_{i i}\right)^{2} A_{i}}{\eta_{i}} f\left(C_{i}\right)
\end{array}\right] .
$$

The leading principle minors of the Hessian matrix are as follows: $-\left(A_{i} / \eta_{i}\right) f\left(C_{i}\right)<0$ and $\left(H_{i} A_{i} / \eta_{i}\right) f\left(C_{i}\right)>0$, which implies that the Hessian matrix is strictly negative, and therefore $C_{\eta_{i}}\left[\pi_{i}^{r}\right]$ is a strictly differentiable concave function on $\left(q_{i}, e_{i}\right)$.

Proof of Theorem 2. From Property 1, it is known that the first-order partial derivative of $C_{\eta_{i}}\left[\pi_{i}^{r}\right]$ with respect to $q_{i}$ and $e_{i}$ satisfies the following conditions:

$$
\begin{aligned}
& \frac{\partial C_{\eta_{i}}\left[\pi_{i}^{r}\right]}{\partial q_{i}}=B_{i}-\frac{A_{i}}{\eta_{i}} F\left(C_{i}\right)=0, \\
& \frac{\partial C_{\eta_{i}}\left[\pi_{i}^{r}\right]}{\partial e_{i}}=-G_{i}\left(e_{i}\right)+\frac{m_{i i} A_{i}}{\eta_{i}} F\left(C_{i}\right)=0 .
\end{aligned}
$$

With some algebra, retailer $i$ 's optimal option ordering policy can be obtained as follows:

$$
\begin{aligned}
& q_{i}^{*}=d_{i}\left(e_{i}^{*}, e_{3-i}\right)+F^{-1}\left(G_{\eta_{i}}\right), \\
& e_{i}^{*}=G_{i}^{-1}\left(m_{i i} B_{i}\right) .
\end{aligned}
$$

Substituting $\left(q_{i}^{*}, e_{i}^{*}\right)$ into (6) leads to the following: $C_{\eta_{i}}^{*}\left[\pi_{i}^{r}\left(q_{i}^{*}, e_{i}^{*}\right)\right]=\left(A_{i} / \eta_{i}\right) \int_{0}^{G_{\eta_{i}}} F^{-1}(t) d t+B_{i} d_{i}\left(e_{i}^{*}, e_{3-i}\right)-g_{i}\left(e_{i}^{*}\right)$, where $G_{\eta_{i}}=\left(B_{i} / A_{i}\right) \eta_{i}, m_{i i}=d_{i e_{i}}^{\prime}\left(e_{i}, e_{3-i}\right)$, and $t=F(x)$.
Proof of Property 2. According to (A.8), it is known that $q_{i}^{*}=d_{i}\left(e_{i}^{*}, e_{3-i}\right)+F^{-1}\left(G_{\eta_{i}}\right)$. With some algebra, it can be determined that $\left(\left(P_{i}-E_{i}-O_{i}\right) /\left(P_{i}-E_{i}\right)\right) \eta_{i}=F\left(q_{i}^{*}-d_{i}\left(e_{i}^{*}, e_{3-i}\right)\right)$. Using the chain rule for the derivative and $f\left(C_{i}\right)>0$, the partial derivative of $q_{i}^{*}$ on $\eta_{i}, O_{i}$, and $E_{i}$ can be obtained as follows:

$$
\begin{aligned}
& \frac{\partial q_{i}^{*}}{\partial O_{i}}=-\frac{\eta_{i}}{A_{i}} \cdot \frac{1}{f\left[q_{i}^{*}-d_{i}\left(e_{i}^{*}, e_{3-i}\right)\right]}<0, \\
& \frac{\partial q_{i}^{*}}{\partial E_{i}}=-\frac{O_{i} \eta_{i}}{\left(A_{i}\right)^{2}} \cdot \frac{1}{f\left[q_{i}^{*}-d_{i}\left(e_{i}^{*}, e_{3-i}\right)\right]}<0, \\
& \frac{\partial q_{i}^{*}}{\partial \eta_{i}}=\frac{B_{i}}{A_{i}} \cdot \frac{1}{f\left[q_{i}^{*}-d_{i}\left(e_{i}^{*}, e_{3-i}\right)\right]}>0 .
\end{aligned}
$$

According to (A.8) and the assumption in Section 3, $\partial q_{i}^{*} / \partial e_{3-i}=d\left[d_{i}\left(e_{i}^{*}, e_{3-i}\right)\right] / d e_{3-i}<0$. The desired result follows, and the proof is complete.

Proof of Theorem 3. From Property 1, it is known that $C_{\eta_{i}}\left[\pi_{i}^{r}\right]$ is strictly concave on $\left(q_{i}, e_{i}\right)$ and that the strategy space $[0,+\infty) \times[0,+\infty)$ of retailer $i$ is a compact convex set. Therefore, there is a pure strategy Nash equilibrium between the two retailers. Furthermore, the equilibrium strategy of the two retailers in the game must be inside the space, and therefore the balance of the game is unique [40].

Proof of Property 3. Note that $q_{i}^{*}>q_{i}^{m}>0, f\left[q_{i}^{m}-\right.$ $\left.d_{i}\left(e_{i}^{*}, e_{3-i}\right)\right]>0$, and $0<\bar{F}(x)<1$. From (13), the first-order and second-order partial derivatives of $E\left[\pi_{i}^{m}\right]$ on $q_{i}^{m}$ and the first-order partial derivative of $E\left[\pi_{i}^{m}\right]$ on $O_{i}, E_{i}, C$, and $Z_{i}$ can be obtained as follows:

$$
\begin{aligned}
\frac{\partial E\left[\pi_{i}^{m}\right]}{\partial q_{i}^{m}} & =-C+Z_{i}-Z_{i} F\left[q_{i}^{m}-d_{i}\left(e_{i}^{*}, e_{3-i}\right)\right], \\
\frac{\partial^{2} E\left[\pi_{i}^{m}\right]}{\partial\left(q_{i}^{m}\right)^{2}} & =-Z_{i} f\left[q_{i}^{m}-d_{i}\left(e_{i}^{*}, e_{3-i}\right)\right]<0, \\
\frac{\partial E\left[\pi_{i}^{m}\right]}{\partial O_{i}} & =q_{i}^{*}>0, \\
\frac{\partial E\left[\pi_{i}^{m}\right]}{\partial E_{i}} & =d_{i}\left(e_{i}^{*}, e_{3-i}\right)+\int_{0}^{q_{i}^{*}-d_{i}\left(e_{i}^{*}, e_{3-i}\right)} \bar{F}(x) d x \\
& >0, \\
\frac{\partial E\left[\pi_{i}^{m}\right]}{\partial C} & =-\left(q_{1}^{m}+q_{2}^{m}\right)<0, \\
\frac{\partial E\left[\pi_{i}^{m}\right]}{\partial Z_{i}} & =-\int_{q_{i}^{m}-d_{i}\left(e_{i}^{*}, e_{3-i}\right)}^{q_{i}^{*}-d_{i}\left(e_{i}^{*}, e_{3-i}\right)} \bar{F}(x) d x<0 .
\end{aligned}
$$

The desired result follows and the proof is complete.

Proof of Theorem 4. The optimal decision of the supply chain system-wide can be used as a benchmark to search for the coordination conditions. First, if $q_{i}^{*}=q_{i}^{s *}$, then $e_{i}^{*}=e_{i}^{s *}$, 
$d_{i}^{*}=d_{i}^{s *}$, and $G_{\eta_{i}}=G_{i}^{s}$; that is, $\left(\left(P_{i}-E_{i}-O_{i}\right) /\left(P_{i}-E_{i}\right)\right) \eta_{i}=$ $\left(P_{i}-C\right) / P_{i}$. Then the following result can be obtained:

$$
\begin{aligned}
1-\frac{C}{P_{i}} & <\eta_{i} \leqslant 1, \\
P_{i} & =E_{i}+\frac{P_{i} O_{i} \eta_{i}}{C-P_{i}\left(1-\eta_{i}\right)}, \\
m_{i i} & =\frac{B_{i}^{s} m_{i i}^{s}+B_{3-i}^{s} m_{3-i, i}^{s}}{B_{i}} .
\end{aligned}
$$

Based on the equilibrium competition, every retailer will compete with the supplier at the same time. If $q^{m *}=\sum_{i=1}^{2} q_{i}^{s}$, then $q^{m *}=\sum_{i=1}^{2} q_{i}^{m \Delta}$, or $q^{m *}=q_{1}^{m \Delta}+q_{2}^{m *}$, or $q^{m *}=$ $q_{1}^{m *}+q_{2}^{m \Delta}$, but $q^{s}<\sum_{i=1}^{2} q_{i}^{*}$, which is in conflict with $q^{s}=q_{i}^{*}$. Therefore, the supplier must satisfy each retailer's optimal ordering quantity, that is, $q^{m *}=\sum_{i=1}^{2} q_{i}^{*}$, which indicates that $Z_{i} \geqslant \widehat{Z}_{i}$. Moreover, for $\widehat{Z}_{i}=P_{i}, Z_{i} \geqslant P_{i}$.

Proof of Theorem 5. It is similar to the proof of Theorem 4.

\section{Conflict of Interests}

The authors declare that there is no conflict of interests regarding the publication of this paper.

\section{Acknowledgment}

This research has been supported by the National Natural Science Foundation of China under Grant 61273233.

\section{References}

[1] X. Chen, G. Hao, and L. Li, "Channel coordination with a lossaverse retailer and option contracts," International Journal of Production Economics, vol. 150, pp. 52-57, 2014.

[2] D. Barnes-Schuster, Y. Bassok, and R. Anupindi, "Coordination and flexibility in supply contracts with options," Manufacturing and Service Operations Management, vol. 4, no. 3, pp. 171-207, 2002.

[3] B. A. Pasternack, "Optimal pricing and return policies for perishable commodities," Marketing Science, vol. 27, no. 1, pp. 133-140, 2008.

[4] A. A. Tsay and W. S. Lovejoy, "Quantity flexibility contracts and supply chain performance," Manufacturing and Service Operations Management, vol. 1, no. 2, pp. 89-111, 1999.

[5] M. Lariviere, "Inducing forecast revelation through restricted returns. EB/OL," 2002, http://bctim.wust1.edu/calendar/mediafiles/Forecasts 2002.pdf.

[6] T. A. Taylor, "Supply chain coordination under channel rebates with sales effort effects," Management Science, vol. 48, no. 8, pp. 992-1007, 2002.

[7] C. L. Munson and M. J. Rosenblatt, "Coordinating a three-level supply chain with quantity discounts," IIE Transactions, vol. 33, no. 5, pp. 371-384, 2001.

[8] H. Gurnani, "A study of quantity discount pricing models with different ordering structures: order coordination, order consolidation, and multi-tier ordering hierarchy," International Journal of Production Economics, vol. 72, no. 3, pp. 203-225, 2001.
[9] Y. Duan, J. Luo, and J. Huo, "Buyer-vendor inventory coordination with quantity discount incentive for fixed lifetime product," International Journal of Production Economics, vol. 128, no. 1, pp. 351-357, 2010.

[10] G. P. Cachon and M. A. Lariviere, "Supply chain coordination with revenue-sharing contracts: strengths and limitations," Management Science, vol. 51, no. 1, pp. 30-44, 2005.

[11] Q. Fu, C.-Y. Lee, and C.-P. Teo, "Procurement management using option contracts: random spot price and the portfolio effect," IIE Transactions, vol. 42, no. 11, pp. 793-811, 2010.

[12] C. X. Wang and S. Webster, "Channel coordination for a supply chain with a risk-neutral manufacturer and a loss-averse retailer," Decision Sciences, vol. 38, no. 3, pp. 361-389, 2007.

[13] X. Wang and L. Liu, "Coordination in a retailer-led supply chain through option contract," International Journal of Production Economics, vol. 110, no. 1-2, pp. 115-127, 2007.

[14] Y. Zhao, S. Wang, T. C. E. Cheng, X. Yang, and Z. Huang, "Coordination of supply chains by option contracts: a cooperative game theory approach," European Journal of Operational Research, vol. 207, no. 2, pp. 668-675, 2010.

[15] Y. Zhao, L. Ma, G. Xie, and T. C. E. Cheng, "Coordination of supply chains with bidirectional option contracts," European Journal of Operational Research, vol. 229, no. 2, pp. 375-381, 2013.

[16] J. Cole, Boeing's Surplus Lot Filling Up, Seattle Times, 1998.

[17] P. H. Ritchken and C. S. Tapiero, "Contingent claims contracting for purchasing decisions in inventory management," Operations Research, vol. 34, no. 6, pp. 864-870, 1986.

[18] A. A. Tsay, "The quantity flexibility contract and supplier-customer incentives," Management Science, vol. 45, no. 10, pp. 13391358,1999

[19] A. Burnetas and P. Ritchken, "Option pricing with downwardsloping demand curves: the case of supply chain options," Management Science, vol. 51, no. 4, pp. 566-580, 2005.

[20] B. Xu, Y. Jia, and L. Liu, "The decision models and coordination of supply chain with one manufacturers and two retailers based on CVaR criterion," Journal of Shandong University (Natural Science), vol. 48, no. 7, pp. 101-110, 2013.

[21] M. E. Schweitzer and G. P. Cachon, "Decision bias in the newsvendor problem with a known demand distribution: experimental evidence," Management Science, vol. 46, no. 3, pp. 404420, 2000.

[22] K. Maccrimmon and D. A. Wehrung, Taking Risks: The Management of Uncertainty, Free Press, New York, NY, USA, 1986.

[23] M. Fisher and A. Raman, "Reducing the cost of demand uncertainty through accurate response to early sales," Operations Research, vol. 44, no. 1, pp. 87-99, 1996.

[24] T. H. Ho and J. Zhang, "Designing pricing contracts for boundedly rational customers: does the framing of the fixed fee matter?" Management Science, vol. 54, no. 4, pp. 686-700, 2008.

[25] T. Feng, L. R. Keller, and X. Zheng, "Decision making in the newsvendor problem: a cross-national laboratory study," Omega, vol. 39, no. 1, pp. 41-50, 2011.

[26] X. Gan, S. P. Sethi, and H. Yan, "Coordination of supply chains with risk-averse agents," Production and Operations Management, vol. 13, no. 2, pp. 135-149, 2004.

[27] H. Xu, "Managing production and procurement through option contracts in supply chains with random yield," International Journal of Production Economics, vol. 126, no. 2, pp. 306-313, 2010. 
[28] C. A. Ingene and M. E. Parry, "Coordination and manufacturer profit maximization: the multiple retailer channel," Journal of Retailing, vol. 71, no. 2, pp. 129-151, 1995.

[29] V. Padmanabhan and I. P. L. Png, "Manufacturer's return policies and retail competition," Marketing Science, vol. 16, no. 1, pp. 81-94, 1997.

[30] Z. Yao, Y. Wu, and K. K. Lai, "Demand uncertainty and manufacturer returns policies for style-good retailing competition," Production Planning \& Control, vol. 16, no. 7, pp. 691-700, 2005.

[31] T. Xiao, G. Yu, Z. Sheng, and Y. Xia, "Coordination of a supply chain with one-manufacturer and two-retailers under demand promotion and disruption management decisions," Annals of Operations Research, vol. 135, pp. 87-109, 2005.

[32] T. Xiao and X. Qi, "Price competition, cost and demand disruptions and coordination of a supply chain with one manufacturer and two competing retailers," Omega, vol. 36, no. 5, pp. 741-753, 2008.

[33] R. T. Rockafellar and S. Uryasev, "Optimization of conditional value-at-risk," Journal of Risk, vol. 2, pp. 21-42, 2000.

[34] R. T. Rockafellar and S. Uryasev, "Conditional value-at-risk for general loss distributions," Journal of Banking \& Finance, vol. 26, no. 7, pp. 1443-1471, 2002.

[35] L. Yang, M. Xu, G. Yu, and H. Zhang, "Supply chain coordination with CVaR criterion," Asia-Pacific Journal of Operational Research, vol. 26, no. 1, pp. 135-160, 2009.

[36] X. Chen, S. Shum, and D. Simchi-Levi, "Stable and coordinating contracts for a supply chain with multiple risk-averse suppliers," Production and Operations Management, vol. 23, no. 3, pp. 379392, 2014.

[37] M. Wu, S. X. Zhu, and R. H. Teunter, "A risk-averse competitive newsvendor problem under the CVaR criterion," International Journal of Production Economics, vol. 156, pp. 13-23, 2014.

[38] C.-C. Hsieh and Y.-T. Lu, "Manufacturer's return policy in a two-stage supply chain with two risk-averse retailers and random demand," European Journal of Operational Research, vol. 207, no. 1, pp. 514-523, 2010.

[39] Z. Liu, L. Chen, and X. Zhai, "Supply chain coordination based on option contract and risk-averse retailers," Systems Engineering, vol. 31, no. 9, pp. 63-67, 2013.

[40] N. Matsubayashi and Y. Yamada, "A note on price and quality competition between asymmetric firms," European Journal of Operational Research, vol. 187, no. 2, pp. 571-581, 2008. 


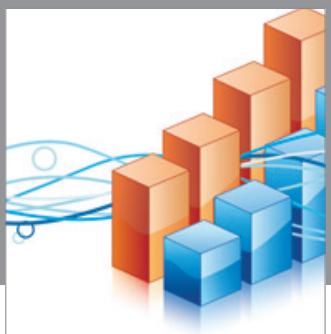

Advances in

Operations Research

vatem alat4

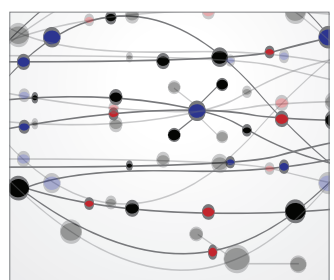

\section{The Scientific} World Journal
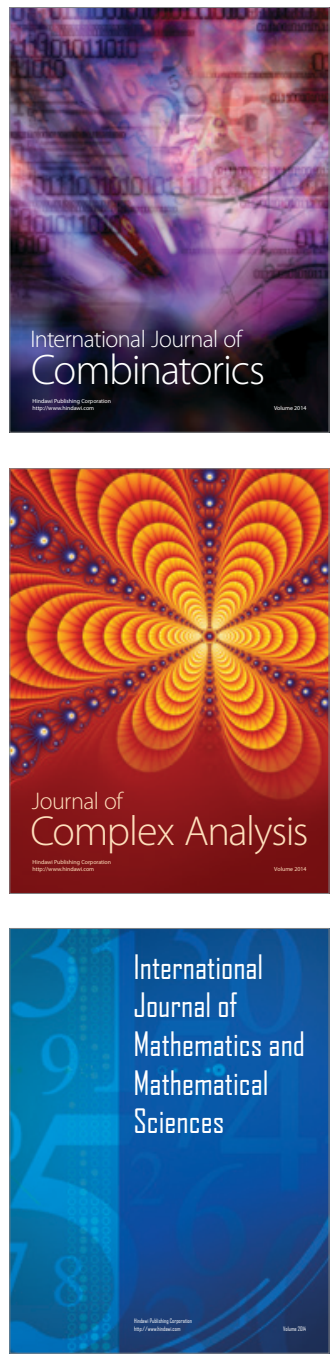
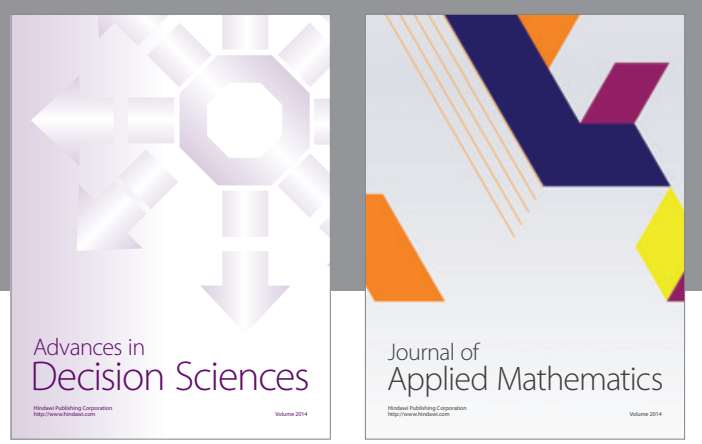

Algebra

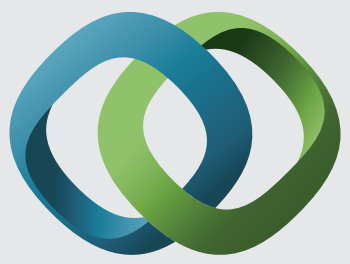

\section{Hindawi}

Submit your manuscripts at

http://www.hindawi.com
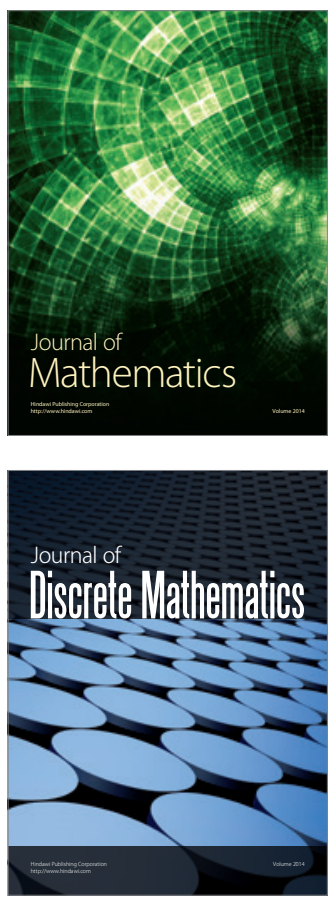

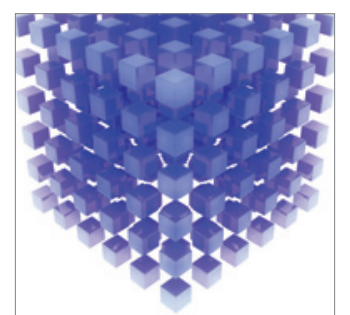

Mathematical Problems in Engineering
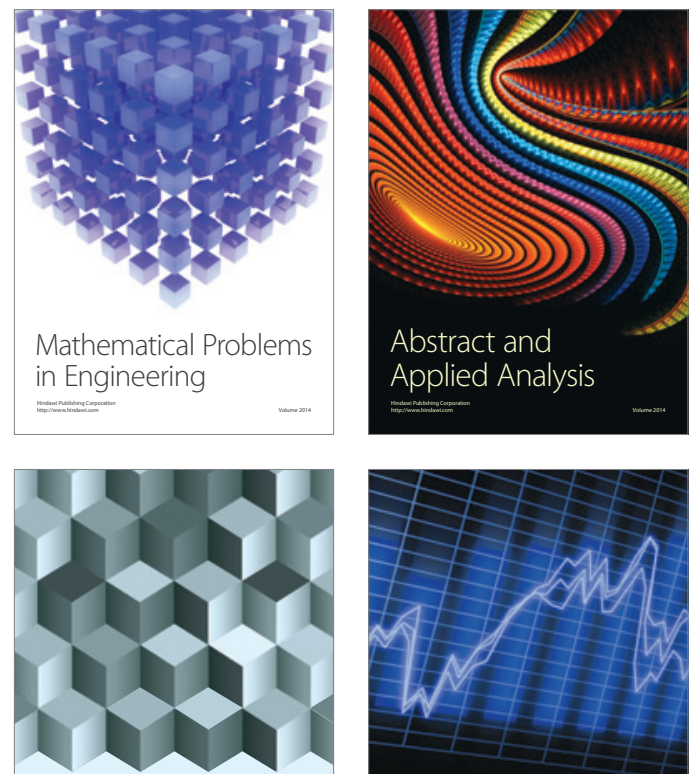

Journal of

Function Spaces

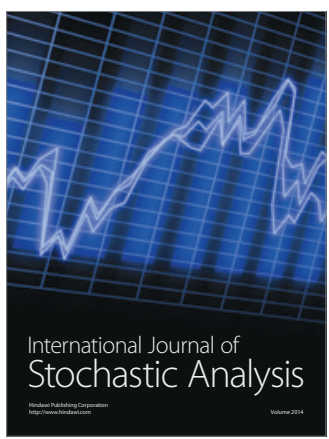

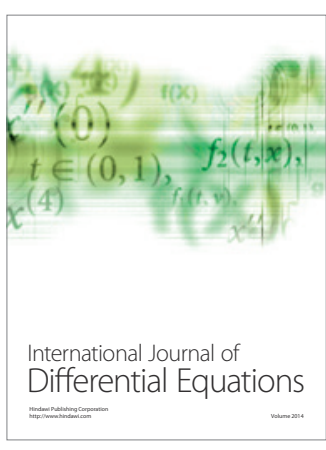
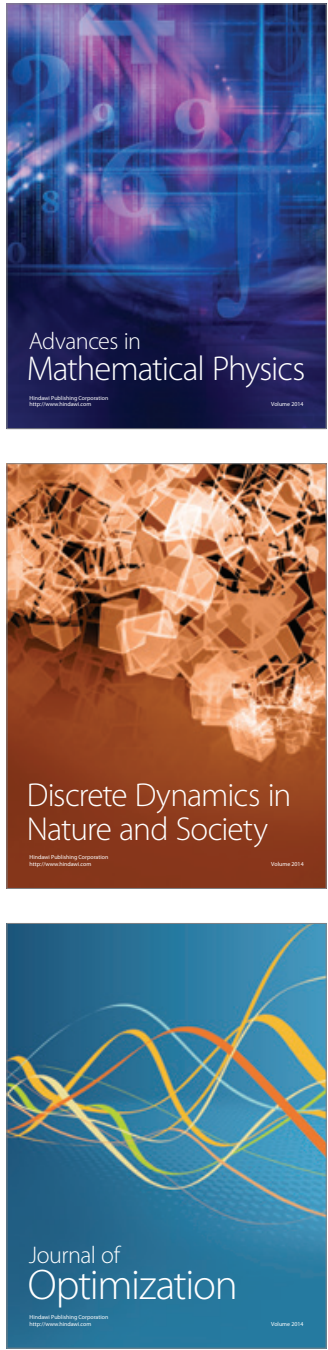